\title{
High-resolution bushfire hazard mapping of the current and future climate to inform planning for the Rockhampton region
}

\author{
R.P. Cechet, L.A. Sanabria, I. French, R. Dunsmore and D. Moore \\ Environmental Geoscience Division, Geoscience Australia, Canberra, 2609 Australia \\ Email: bob.cechet@ga.gov.au
}

\begin{abstract}
The dry-tropics of central Queensland has an annual bushfire threat season that generally extends from September to November. This study aimed to identify the bushfire hazard at the local scale in the Rockhampton region under current and future-climate conditions. It draws on General Circulation Model (GCM) simulations, and builds on those outputs by applying a novel hazard modelling technique to develop an understanding of bushfire hazard at the local level in the Rockhampton region. Fire weather hazard is quantified using either the Forest Fire Danger Index (FFDI) or the Grassland Fire Danger Index (GFDI) (Luke and McArthur, 1978). In these, weather observations (temperature, relative humidity and wind speed) are combined with an estimate of the fuel state to predict likely fire behavior if an ignition occurs.
\end{abstract}

For current climate, the average recurrence interval (ARI) of FFDI at Rockhampton Airport was calculated from observations by fitting the Generalised Extreme Value (GEV) distribution known as the Generalised Pareto Distribution (GPD). A high resolution numerical weather model (dynamic downscaling) was utilised to provide spatial texture of weather over the Rockhampton region for days where bushfire hazard (as measured at the Rockhampton Airport meteorological station) was known to be severe to extreme. Each of these FFDI grids then was normalised to the value of the FFDI at the grid point corresponding to Rockhampton Airport, and an ensemble average was produced which related to the 50 and 100 year ARI for the FFDI for the Rockhampton region (current climate).

For future climate, we considered three downscaled GCM's forced by the A2 greenhouse gas (GHG) emission scenario. The spatial pattern of the 50 and 100 year ARI FFDI for the Rockhampton region (future climate) was determined from the ensemble average of the 2050 and 2090 period GCM outputs. In general, a small spatial increase in the FFDI was reflected in the ensemble model average for 2050 through to the 2090 climate. This was reflected throughout the Rockhampton region in both magnitude and extent through 2050 to 2090. Cluster areas of higher (future climate) bushfire hazard were mapped for local council planning consideration.

To determine bushfire hazard, the FFDI alone does not provide the complete picture of fire hazard. FFDI needs to be combined initially with a weighting based on the vegetation type because FFDI is based solely on forested vegetation. This weighting was derived from a vegetation map of the region. The map was created using a supervised classification of LANDSAT TM imagery and merging of the classified layers into a small number of discrete groups. Combining FFDI and vegetation, and applying the classifications developed for the new fire danger rating system by the National Bushfire Warnings Taskforce, (established following the Victorian bushfires of February 2009), a bushfire hazard map was produced. This bushfire hazard map also required details of where the bushfire hazard was considered to be above the levels allowable for future development. To address this, two factors were added, "setback from closed forest" and "slope", to introduce buffer regions where development should not occur.

This study did not carry out a formal analysis of the assets at risk from bushfire, but such an analysis could be undertaken using the digital data produced. The Rockhampton region was already characterised by high hazard levels for a range of hazards. The region has a history of cyclonic winds and storm surge events, as well as bushfires and frequent flooding. This study formed part of a Rockhampton Regional Council project that aimed to evaluate the ability of its existing urban planning principles and practices to accommodate climate change and the uncertainty of climate change impacts (Moore et al. 2013). The results of this study provide an assessment of local bushfire hazard from extreme events for a particular emissions scenario. Land use planning should consider how the projected future hazard level would impact on proposed development.

Keywords: $\quad$ hazard mapping, bushfire hazard, fire danger, FFDI, recurrence interval 


\section{INTRODUCTION}

The dry-tropics of central Queensland experience an annual significant bushfire threat period that generally extends from September to November. Considering global warming, climate science indicates that as the average temperature increases, heat waves will become more intense, longer and cover a larger region (Trenberth 2007). Droughts are made more intense by higher temperatures, which dry out the soil. More intense droughts have been predicted to occur as the planet warms (CSIRO and BoM, 2012). Wildfires are worsened by drought and by heat waves, therefore longer wildfire seasons and more intense fires are predicted. Australia has experienced increases in average maximum and minimum temperatures of $0.6^{\circ} \mathrm{C}$ and $1.2^{\circ} \mathrm{C}$ respectively over the last century (Hennessy et al. 2007). Furthermore, the rate of warming appears to be increasing globally (Trenberth 2007). Concurrent changes in precipitation and other environmental factors influence fire regimes which are likely to have a significant effect on bushfire risk to urban and peri-urban communities, as well as major impact on the diversity and distribution of species and ecosystems. Australian climate change projections based on the Intergovernmental Panel on Climate Change (IPCC) information (Whetton 2011) indicate a substantial increase in the number of days with maximum temperatures in excess of $35^{\circ} \mathrm{C}$ for a range of capital cities and major regional centres. Projections also indicate longer periods of extreme heat and more severe droughts interspersed with wetter phases leading to flooding.

A recent report "Turn down the heat: Why a $4^{\circ} \mathrm{C}$ warmer world must be avoided" (World Bank 2012) warns that the world will heat up by $4^{\circ} \mathrm{C}$ by the end of the century if the global community fails to act on climate change. Based on the information given above, this study investigated the impact of climate change on bushfire hazard considering the IPCC Special Report on Emissions Scenarios (SRES) A2 GHG emissions scenario (Nakicenovic and Swart, 2000). This projects an average global warming of $3.8^{\circ} \mathrm{C}$ and a range of $2.7-4.7^{\circ} \mathrm{C}$ from the results of a number of complex climate models with a range of climate sensitivities (IPCC, 2007). Three GCM projections utilising the A2 GHG emissions scenario were employed to consider the future climate of the Rockhampton region. The climate change projections utilised indicate that the Rockhampton region is likely to become hotter and possibly slightly drier in the future.

\section{METHODOLOGY}

In Australia, fire weather hazard is quantified using either the Forest Fire Danger Index (FFDI) or the Grassland Fire Danger Index (GFDI) (Luke and McArthur 1978). For this study only FFDI was calculated and the GFDI was scaled from the historical GFDI/FFDI measurements (for days where FFDI $>50$ ). FFDI depends on four variables: drought factor, wind speed, relative humidity and temperature (Noble 1980). The drought factor is used for forests to estimate fuel state, based on daily rainfall and the period elapsed since the last rain. It is based on the Griffiths (1999) formulation which uses the Keetch Byram Drought Index (KBDI; Keetch and Byram, 1968) and was derived by the Bureau of Meteorology (Finkele et al. 2006).

For current climate, the 50 and 100 year average recurrence interval (ARI; average or expected value of the periods between exceedances of a given variable over a given duration) for FFDI at Rockhampton airport was calculated from the 39 years of weather observations (Lucas, 2010) by fitting an extreme value distribution. For ARIs greater than the length of the record (39 years), the FFDI observations were fitted with a Generalised Extreme Value (GEV) distribution (Generalised Pareto Distribution, GPD; see Coles 2001) permitting the calculation of ARI outside the temporal range of the dataset. The GPD was used to obtain the optimum fit for the tail (extremes) of the FFDI distribution. The GPD has been utilised for ARI analysis for a range of environmental parameters (e.g. Sanabria and Cechet, 2007). It should be noted that the highest observed FFDI value was just outside the upper $95 \%$ confidence limit for the extreme value distribution (GPD) fit to the observed data, which indicates that the occurrence of this extreme fire danger day within the 39 years of data is indeed very rare.

The Rockhampton Airport is not representative of the Rockhampton region's diversity in fuel (vegetation), topography and the impact that the proximity of the sea has on local weather conditions, including temperature and moisture. To consider the spatial variation in FFDI, vegetation data was derived for the region and the varying weather conditions across the region were modelled using dynamic downscaling; (Corney et al., 2010). The observational weather record at Rockhampton Airport was used to determine suitable dates for fine-scale simulation of extreme fire weather conditions using a numerical weather prediction model: Weather Research \& Forecasting model $\left(\mathrm{WRF}^{1}\right)$. Analysis of the observation record at Rockhampton Airport (Jan 1973 - June 2011) determined the worst 20 fire weather days (many with similar characteristics), based on FFDI calculated from daily observations and assuming a constant (in this case, the

\footnotetext{
${ }^{1}$ http://www.wrf-model.org/index.php
} 
maximum) drought factor. Bushfires had occurred in the Rockhampton region on some of these days. From these 20 days, 6 were chosen for high-resolution simulation using the WRF model at 270 metre horizontal resolution over the Rockhampton study region. Boundary conditions for forcing the WRF model were supplied by the U.S. National Center for Environmental Prediction (NCEP) operational analyses ${ }^{2}$.

Weather model output at the grid-point corresponding to the location of Rockhampton Airport and the coastal town of Yeppoon were compared to the observations for the corresponding dates, estimating the magnitude and direction of bias in the simulations and to ascertain the appropriateness, accuracy and timeliness of the numerical weather prediction model results. Comparison of quantiles of simulated and observed temperature, relative humidity and 10 metre height wind speed revealed a good match between the modelled and observed values of the first two elements, but wind speed was significantly underestimated in the simulations. A correction factor was applied to improve the quality of the match between the observed and simulated $10 \mathrm{~m}$ height wind speeds. From the temperature, relative humidity and wind speeds generated by the simulations (and corrected where appropriate), the maximum FFDI for each grid-point on each simulated day was calculated, again using a constant drought factor set to the maximum value (10). Each of these grid-points were then normalised to the value of the FFDI at the grid-point corresponding to Rockhampton Airport - i.e. each grid point defines the ratio of the FFDI at that point relative to the FFDI at Rockhampton Airport. The final output was an average of the six days of FFDI ratio grids, providing the spatial distribution of FFDI across the region for extreme fire weather days. The observed (Rockhampton Airport) ARI of FFDI values (50, 100 years) were then combined with the FFDI ratio maps generated from the weather simulations to provide a spatial representation of the FFDI ARI hazard across the Rockhampton study region.

For future climate, we have considered simulations from three downscaled General Circulation Models (GCM's) forced by the A2 GHG emission scenario for atmospheric greenhouse gas emissions. These were provided by CSIRO (2012), produced using the Conformal-Cubic Atmospheric Model (CCAM; McGregor and Dix, 2008) to downscale far-field forcing provided from the ECHAM, GFDL and MIROC GCMs. For our analysis we considered three periods of the simulation within each of the three models:

- (Dataset 1) 1971 - 1990 (considered as the current climate simulation; existing GHG composition)

- (Dataset 2) 2040 - 2059 (considered as the simulated climate of 2050)

- (Dataset 3) 2080 - 2099 (considered as the simulated climate of 2090)

For each GCM, the results for the 2050 and 2090 simulations were compared with the 'current climate modelled' simulation and a spatial scaling factor calculated for the region. The ratio of spatial FFDI for the GCMs simulated under both GCM-modelled 'current climate' and 'future climate' conditions, was then applied to the current-climate 'observed' spatial bushfire hazard, resulting in a spatial representation of the 'future climate' bushfire hazard.

FFDI alone does not provide the complete picture of fire hazard. FFDI needs to be combined with a weighting based on the vegetation type as FFDI is based solely on forested vegetation. The weighting required was calculated based on the vegetation type created by:

- deriving a regional vegetation map (supervised classification of Landsat 5 TM data from mid-2011)

- classifying and merging the vegetation layers into four classes, Closed Forest (weighting 1.0); Open Forest ${ }^{3}$ (weighting 0.8); Grassland ${ }^{4}$ (weighting 0.7) and None $^{5}$ (weighting 0.0).

Table 1. Fire danger classification.

\begin{tabular}{|l|l|}
\hline Rating & Range \\
\hline Moderate & (FFDI $x$ weighting $>5$ and $\leq 11.9)$ \\
\hline High & $($ FFDI $x$ weighting $\geq 12$ and $\leq 24.9)$ \\
\hline Very High & (FFDI $x$ weighting $\geq 25$ and $\leq 49.9)$ \\
\hline
\end{tabular}

\begin{tabular}{l|l|} 
Rating & Range \\
\hline Severe & $($ FFDI x weighting $\geq 50$ and $\leq 74.9)$ \\
\hline Extreme & $($ FFDI x weighting $\geq 75$ and $\leq 99.9)$ \\
\hline Catastrophic & $($ FFDI $x$ weighting $\geq 100)$
\end{tabular}

\footnotetext{
${ }^{2}$ http://mag.ncep.noaa.gov/NCOMAGWEB/appcontroller

${ }^{3}$ The open forest weighting factor of 0.8 was employed as a fire in this mix of vegetation more closely approximates a grass fire than a forest fire.

${ }^{4}$ For Grasslands the GFDI was not employed to determine the fire weather hazard for the region. Geoscience Australia used the FFDI for the grassland regions and then scaled these values dependent on the observed ratio (average weighting) of the GFDI to FFDI when observed FFDI was greater than or equal to 50 during the period January 1973 to June 2011 (22 occasions in the record). For FFDI > 50 (1973-2011): average weighting $=0.7$

5 'None' consists of regions where the vegetation was classified as urban, unclassified, mudflat or water.
} 
A bushfire hazard map was produced, with symbology classified into the ratings (Table 1) developed for the new fire danger rating system for bushfires by the National Bushfire Warnings Taskforce (a body established following the Victorian bushfires of February 2009). However, this bushfire hazard map does not supply details of where the bushfire hazard is considered to be above the levels allowable for future development. To address this, two factors were added: 'setback from closed forest' and 'slope'. Therefore, the final bushfire hazard map was modified as follows:

- For setback, we allow a setback of $100 \mathrm{~m}$ from closed forest (similar to New South Wales and Victoria) which goes some way to addressing both radiant heat and ember attack. For this analysis, the closed forest areas were extended to include a $100 \mathrm{~m}$ buffer zone.

- For slope, we use AS3959 (2009) which states "development should not occur on land which has a slope of greater than 20 degrees. Most of these areas occur in closed forest and setback areas.

\subsection{Assumptions}

In this study land cover (composition and extent) was maintained at the same level for the whole simulation period (1971-2100), and was not varied with season or year-to-year rainfall variability. In other words vegetation was considered as a static layer in all three models. Therefore the impact of climate change on the vegetation, land use and land cover was not considered, and this may affect the results of this study in various ways. Not only is the bushfire hazard sensitive to changes in fuel, but changes in land cover and land-use directly affect the climate through impacts on energy and water balances of the surface (e.g. Feddema et al., 2005; Mahmood et al., 2010). To improve reliability of results, future-climate models may need to incorporate a range of ecosystem dynamics caused by urbanisation, agriculture, deforestation and episodic disturbances such as fires (Running 2008). Significant episodic events such as tropical cyclones and tropical depressions are known to cause significant vegetation growth and regeneration in the months following their passage through a region, but this was not included in either the vegetative growth or the drought factor used.

\section{RESULTS}

Table 2. The number of days per decade (Rockhampton Airport) when the FFDI is Very High, Severe or exceeds the Extreme threshold. Simulations from three climate models (SIM1=ECHAM, SIM2=GFDL \& SIM3=MIROC) using A2 GHG emissions scenario are considered.

\begin{tabular}{|c|c|c|c|c|c|c|c|c|c|}
\hline Period & \multicolumn{3}{|c|}{$\begin{array}{l}\text { Very High } \\
(\text { FFDI }>25 \& \leq \mathbf{5 0})\end{array}$} & \multicolumn{3}{|c|}{$\begin{array}{l}\text { Severe } \\
(\text { FFDI }>50 \& \leq 75)\end{array}$} & \multicolumn{3}{|c|}{ Extreme (FFDI > 75) } \\
\hline Current Climate (observed) & \multicolumn{3}{|c|}{92} & \multicolumn{3}{|c|}{5} & \multicolumn{3}{|c|}{0.5} \\
\hline Climate Models & SIM1 & SIM2 & SIM3 & SIM1 & SIM2 & SIM3 & SIM1 & SIM2 & SIM3 \\
\hline Current Climate (modelled) & 68 & 52 & 89 & 4.25 & 3.5 & 4.5 & 0.25 & 0.5 & 0.25 \\
\hline 2050 (A2 scenario) & 72 & 70 & 68 & 3.5 & 5.0 & 5.0 & 1.5 & 0 & 0.5 \\
\hline 2090 (A2 scenario) & 116 & 100 & 50 & 6.0 & 8.5 & 3.0 & 1.5 & 1.0 & 0.5 \\
\hline
\end{tabular}

The datasets outlined above were used to determine changes in the fire danger rating relative to the current climate conditions. These results are summarised in Table 2 with reference to the Rockhampton airport site. The daily fire danger rating is 'very high' for FFDI values greater than 25, 'Severe' when FFDI exceeds 50 and 'Extreme' when FFDI exceeds 75. The number of 'Very High' fire danger days (considering the Rockhampton Airport meteorological observing site) generally increases -24 to $+35 \%$ by 2050 and -44 to $+92 \%$ by 2090 (which respect to the modelled current climate). For 'Severe' and 'Extreme' days the increase is -18 to $+43 \%$ and -100 to $+600 \%$ respectively for 2050 and -33 to $+243 \%$ and +200 to $+600 \%$ respectively for 2090. These data show a relatively small change in FFDI with climate change for this central Queensland coastal community, which is consistent with other studies that have considered this region (Lucas et al., 2007; Clarke et al., 2011). However, even small changes in FFDI can constitute a significant increase in extreme outcomes (Table 2) especially when those extremes are rare under current climate.

Figure 1 shows the spatial pattern of the 50 year ARI fire danger rating for the Rockhampton region (current climate). The small spatial increase in the fire danger rating is reflected in Figure 2 considering the ensemble model average for the 2050 climate under an A2 GHG emissions scenario. In general, bushfire hazard increases to a small extent at Rockhampton airport (Table 2). This is reflected throughout the Rockhampton region in both magnitude and extent through 2050 (Fig. 2) to 2090 (Fig. 3). Cluster areas of higher bushfire hazard include: (1) south-west of Gracemere (located $10 \mathrm{~km}$ southwest of the Rockhampton)

(2) north of the Rockhampton township on the eastern side of the Bruce Highway

(3) south of the Rockhampton township on the western side of the Bruce Highway.

Moore et al. (2013) provide further technical and spatial details for this analysis. 


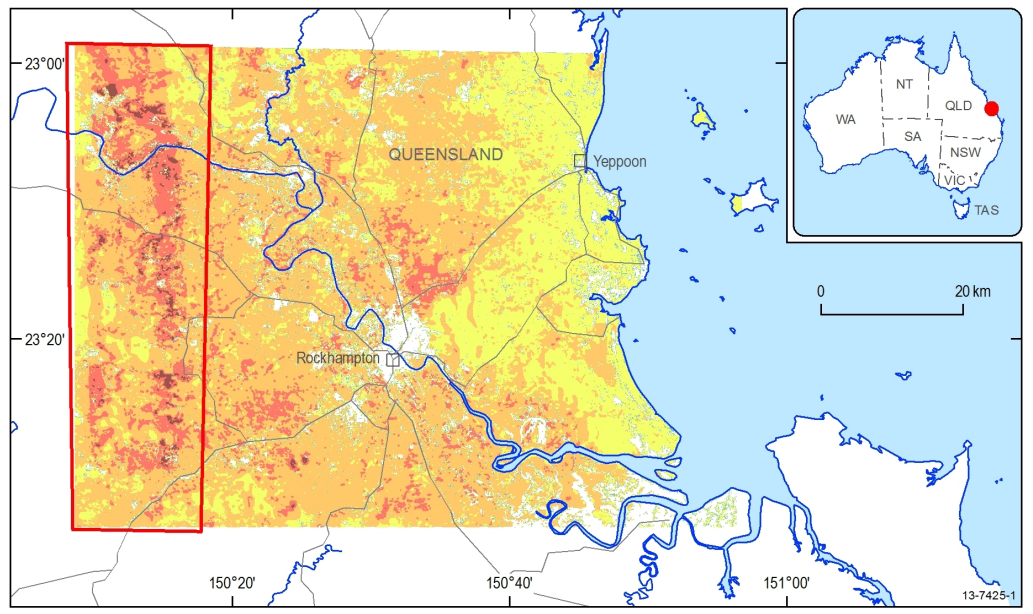

Fire Danger Rating
50 year ARI (average recurrence interval)

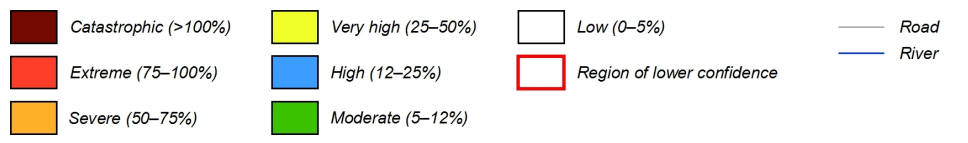

Figure 1. Fire danger rating - current-climate 50 year ARI.

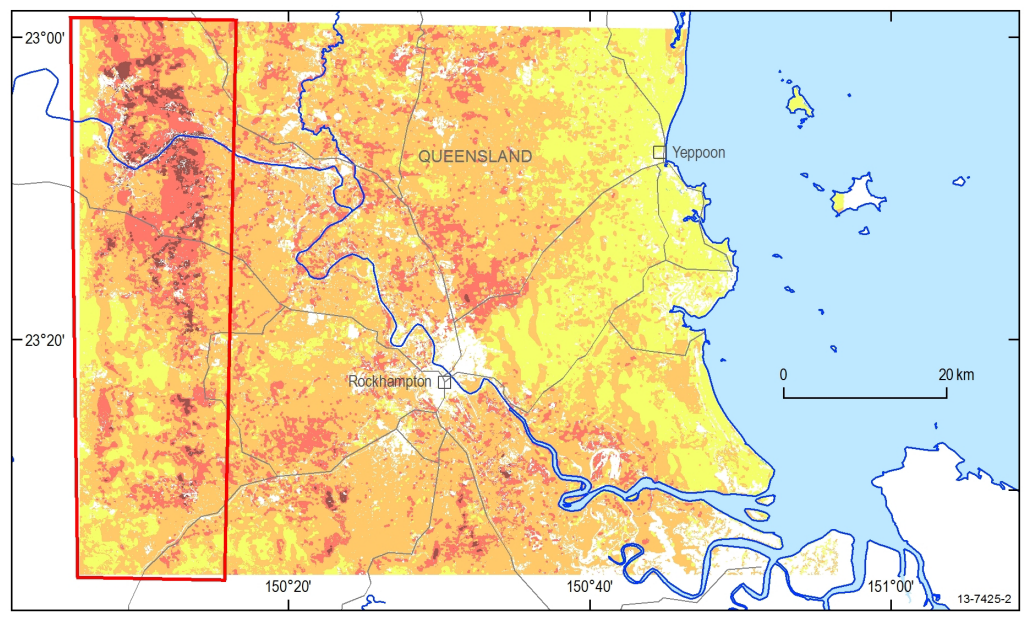

Fire Danger Rating
50 year ARI Three

Figure 2. Fire Danger Rating, 2050 - 50 year ARI (same colour palette as Figure 1)

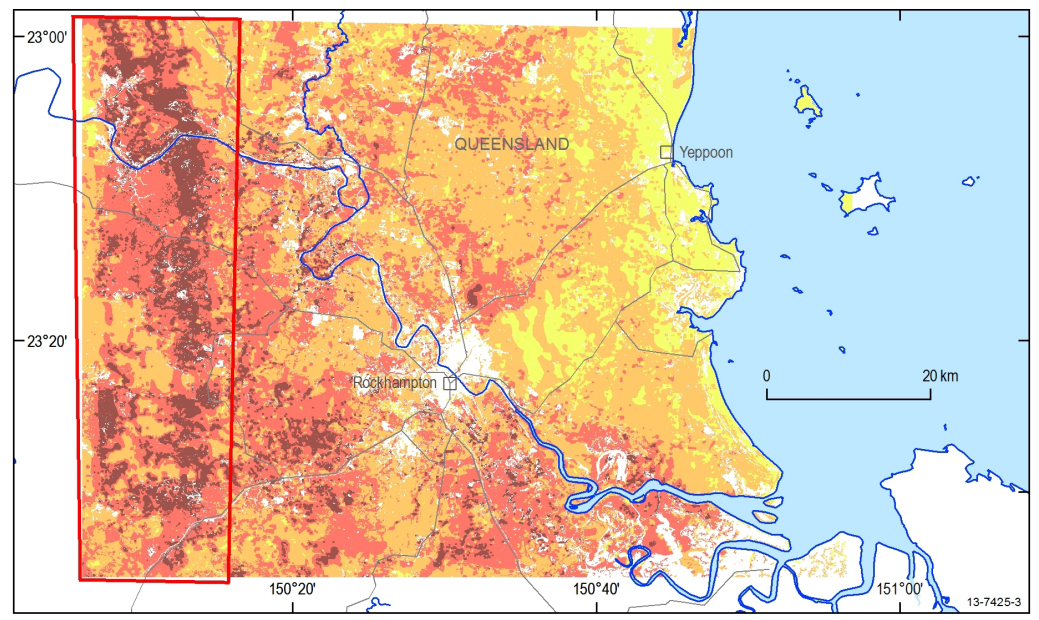

Fire Danger Rating

50 year ARI Two model average (ECHAM and GFDL)

Figure 3. Fire Danger Rating, 2090 - 50 year ARI (same colour palette as Figure 1) 


\section{DISCUSSION}

The area highlighted by the red square in the bushfire hazard maps (Figs. 1, 2 \& 3) depicts a region of lower confidence in the assessment associated with the numerical model and modelling technique utilised. The area of lower confidence has been affected by gravity waves in the modelled atmosphere caused by westerly flows over the nearby mountain ranges (mountain waves). Because their influence on turbulent mixing and on the boundary layer winds is important, gravity waves are included in weather and climate models by parameterisation; this is an active area of research and the methods are evolving. In this study we have averaged the output from six single day downscaled simulations forced by three weather simulations, which is insufficient to average the gravity wave influence in the region of lower confidence. As the weather simulations are an input into the future-climate modelling this issue is therefore present in all the futureclimate results. However, the red highlighted region includes many clusters of extreme and catastrophic risk and therefore the uncertainties need to be reduced. It is unclear how inaccurate these results are without further weather simulations being completed (outside the project timeline). In the region outside the area of lower confidence, the results conform generally with expectations of the spatial distribution of bushfire hazard relating to topography/vegetation and weather characteristics, such as the steep heavily-vegetated areas and the proximity of the ocean increasing the relative humidity and reducing fire hazard.

Excluding the area of lower confidence, the larger regions of less fire hazardous land closer to Rockhampton include the north-west of the Rockhampton township and south of Rockhampton between the Bruce and Capricornia highways (see Moore et al. 2013 for more spatial detail). Notable areas of significant bushfire hazard include the Flat Top Range and to south to the Fitzroy River and the Mount Archer National Park. It should be noted that there is only a small difference in FFDI between the 50 year ARI and 100 year ARI. Most of the region (about 70\%) has a difference below 4 FFDI units, whilst less than $5 \%$ of the region has a difference above 6 FFDI units.

\subsection{Considerations for Further Work}

This initial modelling has the WRF weather variables at 270 metre resolution and the vegetation at 30 metre resolution. To improve the horizontal resolution of the simulations, and to provide greater refinement in the final bushfire hazard maps, either or both the following techniques could be employed:

- Introduce wind multipliers (modifiers) to scale the wind speed down to 30 metre resolution

- Undertake higher resolution modelling by utilising a tiled-grid approach within WRF.

Directional characteristics of historical severe fire spread could also be exploited to inform the setback distance (currently 100 metre buffer in all directions) and direction (i.e. based on dominant wind directions during September to November). Revised hazard levels based on recently available IPCC data should be compared to outputs provided within this report so as to consider the ongoing veracity of the results (considering range of resulting future-climate hazard under representative concentration pathways).

\section{CONCLUSIONS}

This study has provided a preliminary identification of the bushfire hazard in the Rockhampton region under current and future-climate conditions. It draws on available scientific research as well as GCM simulations, and builds on those outputs by applying a hazard modelling technique (employing mesoscale fire weather modelling) to develop an understanding of bushfire hazard at the local level in the Rockhampton region (under both current and future climate conditions). Three GCMs employing the IPCC AR4 A2 GHG emissions scenario, a high-level emissions scenario (Nakicenovic, and Swart, 2000) were utilised. The spatial pattern of the 50 and 100 year ARI fire danger rating for the Rockhampton region (current and future climate) was determined. In general, a small spatial increase in the fire danger rating is reflected in the ensemble model average for the 2090 climate. This is reflected throughout the Rockhampton region in both magnitude and extent through 2050 to 2090. Cluster areas of higher (future climate) bushfire hazard were mapped for local government consideration. The hazard modelling identified the bushfire hazard at a local scale, with outputs aimed at local planning purposes; however they are also suitable for informing potential land development. This study did not carry out a formal analysis of the assets at risk from bushfire, but such an analysis could be undertaken using the digital data produced. This study formed part of a Rockhampton Regional Council project that aimed to evaluate the ability of its existing urban planning principles and practices to accommodate climate change and the uncertainty of climate change impacts (Moore et al., 2013). The results provide an assessment of local bushfire hazard from extreme events for current climate and for a particular high emissions scenario. Land use planning should consider how the projected future hazard level would impact on proposed development. 
Cechet et al., High-resolution bushfire hazard mapping

\section{ACKNOWLEDGMENTS}

The study was partly supported by the National Climate Change Adaptation Research Facility (NCCARF) Settlements and Infrastructure theme as part of the "Reforming Planning Processes Trail: Rockhampton 2050 " project. The authors acknowledge the efforts of Penelope-Jane Fry (Regional Economic Statistics) and Sam Williams (Rockhampton Regional Council) for providing advice/feedback regarding the methodology and products.

\section{REFERENCES}

AS3959 (2009). Construction of buildings in bushfire prone Areas, Standards Australia

Clarke H. G., Smith P. L. and Pitman A. J., (2011). Regional signatures of future fire weather over eastern Australia from global climate models, International Journal of Wildland Fire, 20, 550-562

CSIRO and BoM (2012). State of the Climate 2012. Commonwealth Scientific and Industrial Research Organisation and the Bureau of Meteorology. http://www.csiro.au/Outcomes/Climate/Understanding/State-of-the-Climate-2012.aspx

Coles, S (2001). An Introduction to Statistical Modeling of Extreme Values. Springer Series in Statistics. Springer Verlag London. 208p

Corney, S. P., Katzfey, J. J., McGregor, J. L., Grose, M. R., Bennett, J. C., White, C. J., Holz, G. K., Gaynor, S. M., and Bindoff, N. L., (2010). Climate Futures for Tasmania: climate modelling technical report. Antarctic Climate and Ecosystems Cooperative Research Centre, Hobart, Tasmania.

CSIRO 2012. South East Queensland Climate Adaptation Research Initiative (SEQCARI): Climate Change Projections. http://www.csiro.au/en/Organisation-Structure/Flagships/Climate-Adaptation-Flagship/seqcari/Multi-sector-study.aspx

Feddema, J. J., Oleson, K. W., Bonan, G. B., Mearns, L. O., Buja, L. E., Meehl, G. A., and Washington, W. M., (2005). The importance of land-cover change in simulating future climates. Science, 310, 1674-1678

Finkele, K, Mills GA, Beard G, Jones D (2006). National gridded drought factors and comparison of two soil moisture deficit formulations used in prediction of Forest Fire Danger Index in Australia. Aust. Meteorol. Mag,. 55, 183-197

Griffiths, D. (1999). Improved formula for the drought factor in McArthur's Forest Fire Danger Meter. Australian Forestry 62, 202-206

Hennessy, K., Fitzharris, B., Bates, B. C., Harvey, N., Howden, S. M., Hughes, L., Salinger, J. \& Warrick, R., (2007). Australia and New Zealand. Climate Change 2007: Impacts, Adaptation and Vulnerability. Contribution of Working Group II to the Fourth Assessment Report of the Intergovernmental Panel on Climate Change (eds Parry, M. L., Canziani, O. F., Palutikof, J. P., van der Linden, P. J. and Hanson, C. E.) pp. 507-40. Cambridge University Press

IPCC, 2007 Summary for Policymakers. Climate Change (2007). The Physical Science Basis. Contribution of Working Group I to the Fourth Assessment Report of the Intergovernmental Panel on Climate Change, Cambridge University Press, Cambridge, UK. p14. Available online: http://www.ipcc.ch/pdf/assessment-report/ar4/wg1/ar4-wg1-spm.pdf

Keetch, JJ, and Byram GM (1968). A drought index for forest fire control. USDA Forest Service, Southeast Experiment Station, Research Paper SE-38. (Asheville, NC)

Lucas, C., Hennessy, K., Mills, G. and Bathols, J., (2007). Bushfire weather in southeast Australia: recent trends and projected climate change impacts. Bushfire Cooperative Research Centre and CSIRO Marine and Atmospheric Research. Consultancy Report prepared for The Climate Institute of Australia

Lucas, C., (2010). A historical fire weather dataset for Australia. Aust.Meteorol. and Oceanog. Journal 60, 1-14.

Luke, R. H. and McArthur, A. G., (1978). Bushfires in Australia. Aust. Govt. Publishing Service, Canberra. 359pp

McGregor, J., and Dix, M. R., 2008. An Updated Description of the Conformal-Cubic Atmospheric Model. High Resolution Numerical Modelling of the Atmosphere and Ocean K. Hamilton, and W. Ohfuchi, Eds., Springer 51-75.

Mahmood, R., and Co-authors, (2010). Impacts of land use/land cover change on climate and future research priorities. Bulletin of the American Meteorological Society, 91, 37-46, doi: http://dx.doi.org/10.1175/2009BAMS2769.1

Moore, D., Hazelwood, M., Cechet, R.P., Arthur, W.C., French, I., Dunsmore, R., Sanabria, A., Yang, T., and Woolf, M., (2013). Reforming Planning Processes Trial: Rockhampton 2050 - Technical Report on Current and Future Climate Hazards. Record 2013/15, Geoscience Australia: Canberra.

Nakicenovic, N. and Swart, R., Eds. (2000). Special Report on Emissions Scenarios. IPCC Special Reports. Cambridge, England, Cambridge University Press, 608pp.

Noble, I.R., Bary G.A.A., and Gill A.M. (1980). McArthur's fire danger meters expressed as equations. Australian Journal of Ecology, 5, $201-203$

Running, S. W., (2008). Ecosystem disturbance, carbon, and climate. Science, 321, 652-653

Sanabria, L.A. and R.P. Cechet (2007). A Statistical Model of Severe Winds, Geoscience Australia Record 2007/12

Trenberth, K. E. and others (2007). Observations: Surface and Atmospheric Climate Change. In: Climate Change 2007: The Physical Science Basis. Contribution of Working Group I to the Fourth Assessment Report of the Intergovernmental Panel on Climate Change, Cambridge University Press, Cambridge, UK.

Whetton, P.W., (2011). Future Australian climate scenarios. Chapter 3, Climate Change: Science and Solutions for Australia, CSIRO Publishing, 168pp, Available at http://www.publish.csiro.au/pid/6558.htm

World Bank (2012). "Turn down the heat: Why a $4^{\circ} \mathrm{C}$ warmer world must be avoided", A report for the World Bank by the Potsdam Institute for Climate Impacts Research and Climate Analytics. International Bank for Reconstruction and Development / The World Bank, 106pp

Published with the permission of the CEO. Geoscience Australia

(C) Commonwealth of Australia (Geoscience Australia) 2013 